\title{
Zosteriform cutaneous leishmaniasis
}

\author{
Sim Sai Tin ${ }^{1}$, Viroj Wiwanitkit ${ }^{2}$
}

1 Medical Center, Shantou, China
2 Hainan Medical University, China

Citation: Tin SS, Wiwanitkit V. Zosteriform cutaneous leishmaniasis. Dermatol Pract Concept. 2014;4(4):20. http://dx.doi.org/10.5826/ dpc.0404a20

Received: June 9, 2014; Accepted: September 8, 2014; Published: October 31, 2014

Corresponding author: Sim Sai Tin, Medical Center, Shantou, China. Email: simsaitin@gmail.com

Dear Editor,

We would like to discuss on the report on "Zosteriform cutaneous leishmaniasis" [1] Ramot et al. reported that "dermoscopy has proven to be an accessible and easy tool to diagnose such atypical presentation of cutaneous leishmaniasis, and dermatologists in endemic areas should be familiar with its typical dermoscopic features" [1]. In fact, cutaneous leishmaniasis is an important tropical dermatological infection. To diagnose it, the practitioner has to perform laboratory investigation to confirm the diagnosis [2]. The use of "in vivo confocal microscopy" is presently mentioned as a new noninvasive tool to diagnose cutaneous leishmaniasis $[3,4]$. As noted by Taheri et al., the appearance by dermoscopy of cutaneous leishmaniasis is varied [4]. The "paronychial, annular, palmoplantar, zosteriform, erysipeloid, and sporotrichoid" appearance of cutaneous leishmaniasis is not common and can be easily missed. The limitation in diagnosis seems not due to limitation of the dermoscopy toll but the awareness of the practitioner on the disease, cutaneous leishmaniasis [5]. In endemic areas of cutaneous leishmaniasis, use of dermoscopy in the investigation of any cases of zosteriform cutaneous lesions to rule out cutaneous leishmaniasis is suggested.

\section{References}

1. Ramot Y, Nanova K, Alper-Pinus R, Zlotogorski A. Zosteriform cutaneous leishmaniasis diagnosed with the help of dermoscopy. Dermatol Pract Concept. 2014;4(3):10.

2. Wiwanitkit $\mathrm{V}$. Interest in paromomycin for the treatment of visceral leishmaniasis (kala-azar). Ther Clin Risk Manag. 2012;8:323-8.

3. Alarcon I, Carrera C, Puig S, Malvehy J. In vivo confocal microscopy features of cutaneous leishmaniasis. Dermatology. 2014;228(2):121-4.

4. Taheri AR, Pishgooei N, Maleki M, et al. Dermoscopic features of cutaneous leishmaniasis. Int J Dermatol. 2013;52(11):1361-6.

5. Omidian M, Mapar MA. Chronic zosteriform cutaneous leishmaniasis. Indian J Dermatol Venereol Leprol. 2006;72(1):41-2. 